Integration of order picking and vehicle routing in a B2C e-commerce context Peer-reviewed author version

MOONS, Stef; RAMAEKERS, Katrien; CARIS, An \& Arda, Yasemin (2018)

Integration of order picking and vehicle routing in a B2C e-commerce context. In:

Flexible services and manufacturing journal, 30 (4), p. 813-843..

DOI: $10.1007 / \mathrm{s} 10696-017-9287-5$

Handle: http://hdl.handle.net/1942/23747 


\title{
Integration of order picking and vehicle routing in a B2C e-commerce context
}

\author{
Stef Moons · Katrien Ramaekers · An Caris · \\ Yasemin Arda
}

Received: date / Accepted: date

\begin{abstract}
E-commerce sales are increasing every year and customers who buy goods on the Internet have high service level expectations. In order to meet these expectations, a company's logistics operations need to be performed carefully. Optimizing only internal warehouse processes will often lead to suboptimal solutions. The interrelationship between the order picking process and the delivery process should not be ignored. Therefore, in this study, an order picking problem and a vehicle routing problem with time windows and release dates are solved simultaneously using a single optimization framework. To the best of our knowledge, it is the first time that an order picking problem and a vehicle routing problem are integrated. A mixed integer linear programming formulation for this integrated order picking-vehicle routing problem (OP-VRP) is provided. The integrated OP-VRP is solved for small instances and the results are compared to these of an uncoordinated approach. Computational experiments show that integration can lead to cost savings of $14 \%$ on average. Furthermore, higher service levels can be offered by allowing customers to request their orders later and still get delivered within the same time windows.
\end{abstract}

Keywords integrated problem · order picking · vehicle routing - release dates . e-commerce

\section{Introduction}

In the last decades, a lot of manufacturing plants moved from Europe to countries with low costs to remain competitive (EESC 2003, 2014). This offshoring led to a loss of approximately 3.5 million jobs in the manufacturing industry in the EU since 2008 (EESC 2014). At the same time, many multinational companies built a

S. Moons $(\bowtie) \cdot$ K. Ramaekers · A. Caris

UHasselt - Hasselt University, Research Group Logistics, Agoralaan - Building D, 3590 Diepenbeek, Belgium

E-mail: stef.moons@uhasselt.be Y. Arda

QuantOM, HEC Management School, University of Liège, Rue Louvrex 14, 4000 Liège, Belgium 
distribution center (DC) in Europe. These DCs are generally responsible for the deliveries of goods produced outside Europe to European customers within the context of business-to-consumer (B2C) e-commerce transactions (Hultkrantz and Lumsden 2001). In the last decade, the European B2C e-commerce sales has been growing annually with $12 \%$ on average. More specifically, in 2015, the B2C e-commerce sales grew with approximately $13.5 \%$ in Europe. This expansion of the B2C e-commerce sector has led to the creation of approximately 2.5 million jobs in Europe (Ecommerce Europe 2016).

The rise of e-commerce creates new challenges and opportunities for the logistics system (Richards 2014). New distribution channels and structures arise, which lead to more complex distribution networks. For instance, goods are often transported from a DC to a postal office depot from where the goods are delivered to customers by a mailman, or even delivered directly from a DC to the end customer (Hultkrantz and Lumsden 2001). As such, compared to traditional distribution networks, wholesalers and retailers are often bypassed. Furthermore, in an e-commerce context, customers order more frequently in smaller quantities (Gong and de Koster 2008). As a consequence, the number of consignments increases (Hultkrantz and Lumsden 2001). In Europe, approximately 4.2 billion B2C parcels are sent to customers annually (Ecommerce Europe 2016). This large number of smaller quantities makes it more challenging to consolidate customer orders in an efficient way.

Customers expect a fast and accurate delivery within tight time windows, preferably home delivery, and this at a low cost or even free (de Koster 2003). This free shipping leads to higher costs for companies. Often same day or next day delivery is promised to customers (Gong and de Koster 2008). In order to fulfill these expectations at low costs, excellent logistics performance is indispensable (Hultkrantz and Lumsden 2001). In the first place, internal warehouse processes need to be optimized. Storage location, batching, zoning, and routing decisions in a warehouse should be taken simultaneously as these problems have interdependencies. However, studies in which these problems are integrated are rather scarce (de Koster et al 2007). Moreover, after the (e-commerce) orders are picked in a warehouse, these need to be delivered to customers. Accordingly, order picking and distribution are interrelated. Instead of solving an order picking problem (OPP) and a vehicle routing problem (VRP) separately and sequentially, these two problems can be integrated into a single optimization problem. In an integrated problem, both subproblems are solved simultaneously to obtain an overall optimal solution.

However, nowadays, B2C e-commerce companies often outsource their delivery operations to a third-party logistics (3PL) service operator. Every day, the 3PL operator picks up the goods at the DC at a fixed time, mostly in the evening. Based on the pickup time, the e-commerce company determines a cut-off time. All goods ordered before this cut-off time are picked before the 3PL service provider arrives at the DC. Goods ordered after the cut-off time are handled in the DC before the next pickup time. As can be seen in Fig. 1(a), the order picking process and the delivery process are strictly separated by the pickup time implied by the 3PL service provider. In the integrated approach, the e-commerce company executes the delivery operations itself, or there is coordination between the e-commerce company and the 3PL service provider. No fixed pickup times are implied anymore. By coordinating the order 


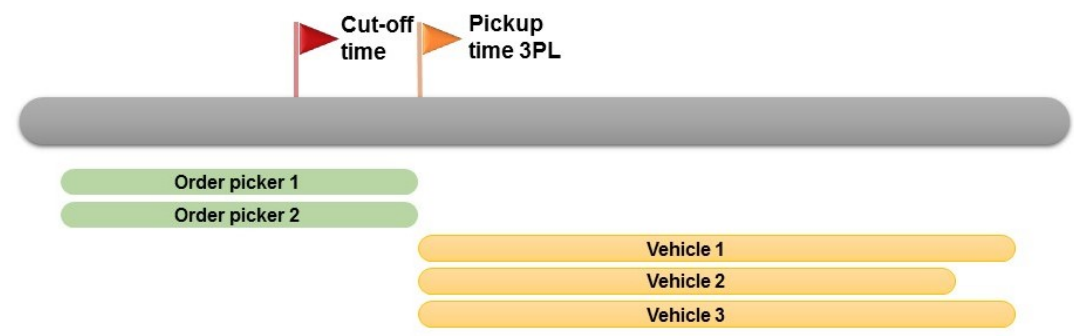

(a) Uncoordinated approach (with 3PL)

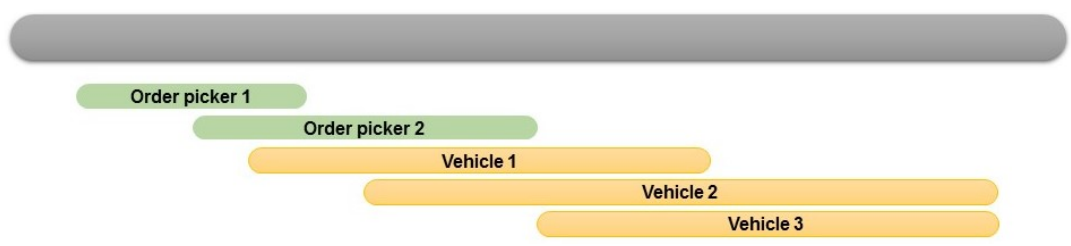

(b) Integrated approach

Fig. 1 Timeline for an uncoordinated and integrated approach

picking and distribution process, and exchanging information, a vehicle can leave the DC whenever a sufficient number of orders to conduct a delivery route are picked. As such, there is more flexibility in the start of the distribution process. The picking and delivery operations overlap in time, as illustrated in Fig. 1(b). A vehicle is already delivering picked orders, while orders which will be delivered by another vehicle are still being picked in the DC. Consequently, goods which are ordered late can possibly still be delivered, whereas in the uncoordinated approach the delivery would be after the next pickup time. The relevance of the integrated problem in a warehouse environment is demonstrated by the example of Amazon, an international e-commerce company. In Germany, Amazon starts with its own package delivery service to deliver customer orders handled in their warehouses instead of outsourcing these activities to a 3PL service provider. By delivering orders itself, Amazon has more flexibility in their delivery services (VerkehrsRundschau 2015).

The focus of this paper is on the integration of a VRP with an OPP for B2C ecommerce sales. As production and warehousing have rather similar characteristics, problems similar to the integrated production scheduling-vehicle routing problems $(P S$-VRPs) can be formulated for the integration of order picking and vehicle routing in a warehouse context. In both problems, jobs need to be assigned to resources in such a way that an objective is met, e.g., cost minimization or service level maximization. However, to the best of the authors' knowledge, no other studies compared these combinatorial optimization problems before.

Historically, production and distribution subproblems are solved sequentially which often leads to suboptimal solutions, as proved by Chen and Vairaktarakis (2005), Park and Hong (2009), and Chang et al (2014). These studies indicate that integration can lead to a solution improvement between $5 \%$ and $20 \%$ compared to an uncoordinated 
approach. Recently, the integration of a production scheduling problem and a VRP at the operational decision level has received more attention in the scientific literature, see e.g., Farahani et al (2012), Amorim et al (2013) and Li et al (2016) among others. A review on and classification of integrated PS-VRPs can be found in Chen (2010) and Moons et al (2017).

The contribution of this paper is threefold: (1) indicating similarities and differences between production scheduling problems and order picking problems in order to being able to translate existing integrated studies in a production context to a warehouse context; (2) formulating an integrated order picking-vehicle routing problem $(O P-V R P)$; and, (3) solving the integrated OP-VRP and measuring the value of an integrated approach over an uncoordinated approach.

The most related studies to our work are Low et al (2013, 2014, in press) and Zhang et al (2016). Low et al (2013, 2014, in press) consider an integration of a practical scheduling problem in a DC with a VRP. However, in our paper, an integrated mathematical model is formulated using the terminology of warehousing instead of production related terminology used in the studies of Low et al (2013, 2014, in press). Additionally, more realistic assumptions are made such as multiple order pickers, loading times, and a limited number of heterogeneous vehicles. Zhang et al (2016) are the only ones who examine an integration of order picking and distribution operations in a B2C e-commerce context. In their study, delivery is outsourced to 3PL service providers. As such, the OPP is integrated with simple distribution operations, and not with a VRP. In our study, however, vehicle routing decisions are explicitly taken into account in the integrated problem. To the authors' knowledge, it is the first time that an OPP and a VRP are integrated.

The remainder of this paper is organized as follows. Sect. 2 compares concepts used in production scheduling problems and order picking problems. In Sect. 3, the problem characteristics of the proposed integrated OP-VRP are explained. Sect. 4 reviews the state-of-the-art literature. Mathematical models are formulated for an order picking problem, a vehicle routing problem with time windows and release dates, and an integrated OP-VRP in Sect. 5. Sect. 6 sets out the computational experiments executed and assesses the value of integration. Finally, in Sect. 7, conclusions and future research directions are presented.

\section{Comparing production and warehousing}

In this paper, order picking and vehicle routing are integrated into a single problem. The most related literature is on the integration of supply chain functions in a production environment. Therefore, the production processes and properties need to be translated to a warehouse context. In research on production and warehousing different terminologies are generally used to describe similar processes. Hence, most production concepts can be easily adapted to warehouse concepts. We focus on the basic concepts of both supply chain functions. It is not our aim to compare all existing production and warehousing concepts. Table 1 gives an overview of the related terminology used in production and warehousing. 
Table 1 Terminology used in production and warehouse context

\begin{tabular}{ll} 
Production context & Warehouse context \\
\hline production & order picking \\
production scheduling & order sequencing \\
job & order \\
task or operation & order line \\
machine & order picker \\
production time & retrieval time/order picking time \\
single or parallel machine scheduling & single order picking \\
single or parallel machine scheduling with $p$-batching & batch picking \\
make to order & pick by line/pick to zero \\
bundling machine environment & synchronized zoning \\
job shop or flow shop & progressive zoning
\end{tabular}

In a manufacturing plant the main activity is production, while in a warehouse it is order picking. Production refers to the processes which transform inputs, such as raw materials, into outputs demanded by customers using resources (Jacobs and Chase 2011). Production scheduling is the process of allocating scarce resources, e.g., machines and employees, to jobs over time to optimize a single or multiple objective(s) (Graves 1981; Lawler et al 1993). For each resource in a production environment a schedule is determined. The schedules of the multiple resources can be represented in a Gantt chart. An example can be found in Fig. 2(a) in which $J i$ represents job $i$.

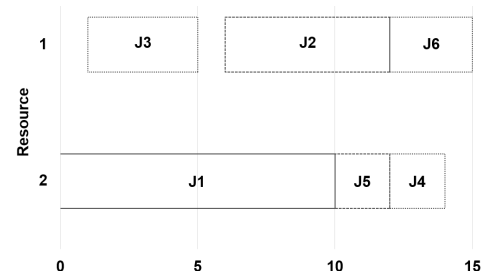

(a) Gantt chart

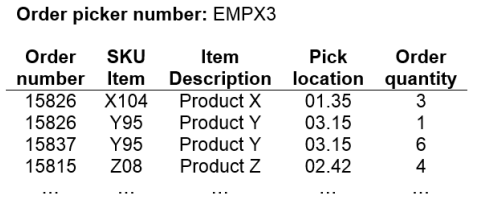

(b) Pick list

Fig. 2 Example of a Gantt chart and a pick list

Order picking is the warehousing process of retrieving products from specific storage locations in a warehouse to satisfy customer requests (Petersen and Schmenner 1999; Henn 2015). Order sequencing is determining the sequence in which the different customer orders should be picked (Elsayed et al 1993) to meet the due date of each order. The result is a pick list for each order picker which indicates the order lines he should pick and in which sequence (Henn et al 2012), as shown in Fig. 2(b).

In order to refer to a customer request, the term job is used in a production environment and the term order is used in a warehouse environment. A job consists of multiple tasks (or operations) which should all be completed before the entire job is finished, while an order consists of order lines, each of which indicating a different product with the corresponding requested quantity and storage location (de Koster et al 1999). 
Both in production and order picking, customer requests need to be assigned to a limited number of resources. Resources in a production context, i.e., machines, can be compared with these in a warehouse, i.e., order pickers. In fact, a resource can be generally defined as a time scale with certain time intervals available (Conway et al 1967) to which jobs or orders can be assigned to be processed and completed for delivery. Furthermore, in both problems, decisions have to be made about the sequence in which the different customer requests should be processed.

The production processing time is the time needed to produce the quantity demanded of a product using the resources. A setup time to prepare a resource to process a job (Allahverdi and Soroush 2008) is often included in the processing time (Allahverdi et al 1999). The order picking processing time (or retrieval time) is the time needed by an order picker to complete a route to pick the items requested in that specific order. The picking time consists of several components: (1) travel time between storage locations which need to be visited; (2) search time to find the required item; (3) pick time to grab the required quantity of items; and, (4) setup time. Travel times are the dominant component in the picking time, responsible for approximately half the total order picking time, while setup times are rather negligible (Tompkins et al 2003; de Koster et al 2007; Henn et al 2012). The setup time in an order picking process is the administrative time at the beginning and end of a picking tour. It includes the time needed for an order picker to obtain a new pick list and an empty picking device at the start point of a tour and to return to this point after completing a tour (Van Nieuwenhuyse and de Koster 2009).

A single order picking policy (or pick-by-order) in which a single order is picked at a time in a warehouse can be compared with, depending on the number of order pickers, single or parallel machine scheduling in the case that each job consists of one task. In a warehouse context, however, order batching (or pick-by-batch or batch picking), in which several orders are picked in a single picking tour by an order picker (de Koster et al 1999, 2007; Henn 2015), is often applied. Order batching in a warehouse can be seen as single or parallel machine scheduling with $p$-batching in a production environment. In p-batching (or parallel batching) jobs are processed simultaneously on a machine. The largest processing time of a job in a batch defines the processing time of the batch (Brucker 2007). However, the picking time of a batch will not be equal to the largest order picking time in the batch. The batch picking time will be larger than the picking time of each individual order in the batch, but in general shorter than the sum of all individual order picking times. In order to determine the picking time a traveling salesman problem for each order or batch needs to be solved.

A specific picking method is pick by line (pick to zero). This picking method is mainly applied in a DC which executes cross-docking operations. In a cross-docking DC, goods are not stored for a long period of time. When goods arrive at the DC, they are immediately sorted and loaded into roll cages for each individual store (or customer) in the required quantities. In contrast to a traditional DC, goods are not assigned to a storage location from which the required number of items is picked (Rushton et al 2001; Fernie and Sparks 2004). Pick by line can be compared to a make to order process in a production environment. In this situation, a manufacturer starts producing after a good has been requested by a customer. Then, the exact number of 
items is produced. Thus, the customer is not being delivered from stock (Jacobs and Chase 2011).

Furthermore, a warehouse can be divided into different zones. Order pickers can only pick items in the zone to which they are assigned. An order can consist of order lines with picking locations in different zones. Consequently, multiple order pickers should work on the order. Two variants of zoning occur. In the first variant, called parallel picking (or synchronized zoning), order pickers of each zone work simultaneously (in parallel) on the same order. In each zone, the order lines of which the storage locations are located in that zone are picked. At the end, the order lines picked in each zone are merged together. Synchronized zoning can be compared with a bundling machine environment in a production context in which $m$ independent tasks of a job need to be processed on $m$ dedicated machines. These $m$ operations need to be bundled together before the job can be delivered (Chen 2010). The tasks of a job which need to be processed on a specific machine can be compared with order lines of an order which need to be picked in specific warehouse zones. The second variant is called progressive zoning (or pick-and-pass or sequential zoning). In contrast to synchronized zoning, an order is picked sequentially in the different zones. One order picker starts with the order. Once all order lines in one zone are picked, the order is passed on to an order picker in another zone (de Koster et al 2007). Progressive zoning can be related to a flow shop or a job shop in a production environment. In a job shop or flow shop, a job is processed on different machines in a specified order. Similar to passing on a job to the next machine in a job shop or flow shop, in progressive zoning an order is passed on to an order picker in the next zone.

The comparison of production and warehouse processes in this section has two objectives: (1) to act as a starting point for describing and formulating an integrated OP-VRP in a warehouse context making use of the existing literature in a production environment; and, (2) to show the relationship between warehousing and production in order to connect the two research communities. It could stimulate the application of concepts and solution approaches in each other's domain.

\section{Problem description}

In this paper, an integrated OP-VRP is investigated to determine an overall solution for both the order picking process and the vehicle routing problem. In a DC, customer orders need to be picked by order pickers. After the orders are picked, they need to be delivered to the customers. Both an order picking schedule and vehicle delivery routes need to be determined. Currently, in most warehouses a fixed due date is being implied before which all orders need to be picked. The due date separates the order picking process and the vehicle routing, and represents the pickup time by a 3PL service provider, or the internal distribution department when there is no coordination. This pickup time implies a cut-off time, which indicates the time before which orders should be placed if they need to be picked up by the vehicle at the pickup time. In the integrated problem, the influence of eliminating this picking due date is examined. To the best of our knowledge, it is the first time an OPP and a VRP are incorporated into a single optimization problem. The studies of Low et al (2013, 2014, in press) are 
the most related to our problem in spite of the fact that they make use of terminology used in production environment and make some less realistic assumptions, as will be illustrated in Sect. 4.3.

The following assumptions related to the DC are made. A number of order pickers work in parallel in a single zone to pick items requested by customers. The order pickers may have picking devices with different capacities and are available at time 0 . The wage of an order picker per time unit worked is taken into account. Additional temporary order pickers can be hired in case of a high customer demand. The wage of a temporary order picker is higher than that of a regular order picker due to the uncertainty they have about their work and to value their flexibility. Furthermore, a maximum number of order pickers can work at a time to avoid congestion in the aisles of the warehouse. A picker-to-product system is used, i.e., manual order pickers travel along the picking locations (van den Berg 1999). Splitting of orders over multiple order pickers is not allowed. Each order, consisting of one or more order lines, is picked individually without interruption in a single tour, i.e., single order picking policy. Batching of orders is not applied in the order picking process.

When the picking of a customer order is completed, the corresponding goods are released to be delivered. The distribution operations are executed by a limited number of vehicles which can have different capacities and costs. Both a variable cost per time unit of the tour length, which includes the wage of the driver and the fuel cost, and a fixed cost for using a vehicle are incurred. The fleet is originally located at the DC to which each vehicle should return after a route is completed. The routing is defined on a complete undirected graph. Travel times of the delivery network are symmetric and satisfy the triangle inequality, i.e., $t_{i j}+t_{j k} \geq t_{i k}$. Service times, which are the loading times at the DC and unloading times at the customer locations, are explicitly taken into account.

Each customer has specified a time window in which the delivery of the order should start. In a B2C e-commerce context, the time windows correspond to the time periods indicated during the online purchase process, within which the customers are available to accept the parcel. As such, an early or tardy delivery is not possible. If a vehicle arrives early, it has to wait at the customer's location until the beginning of the time window. A customer order cannot be split, i.e., an order is delivered by a single vehicle. However, different orders of the same customer can be delivered in different routes. An order can be delivered immediately to the corresponding customer after completion of the picking process or different orders can be consolidated into a route. It is assumed that as long as the total physical space of the orders loaded onto a vehicle does not exceed the capacity of that vehicle, a loading plan can be found in which all orders fit into the vehicle.

The described problem is a first attempt to integrate order picking processes and vehicle routing in a $\mathrm{B} 2 \mathrm{C}$ e-commerce environment. Hence, relatively basic formulations are applied, especially for the order picking subproblem. The authors are aware that in a real-world DC the order picking process is more complex. First, several orders are generally batched to be picked in the same route through the warehouse. However, to be able to compute the effective impact of integration, and not the impact of assigning orders to different batches, a single order picking policy is applied in this study. Second, customers can order goods on the Internet 24/7. Thus, demand cannot 
be known in advance and the arrival time of the orders is uncertain. As the described problem is static, the scattering of the order placement over time will be simulated in the computational experiments by using different values for the order dates, which indicate the moment in time that the orders are requested by the customers. Moreover, we do not include recent developments in order picking research. For instance, new picking policies, e.g., pick by line or pick to zero, and routing strategies, e.g., polling-based routing, are not incorporated.

\section{Literature review}

The described problem is an integration of an order picking problem and a vehicle routing problem with release dates. The state-of-the-art literature on both problems as well as on integrated problems is reviewed.

\subsection{Order picking problem}

In a warehouse, order picking is the major cost component as it is a labor-intensive activity (Tompkins et al 2003). In a B2C e-commerce environment a large number of small orders need to be picked, which makes it even more labor-intensive (Agatz et al 2008). Additionally, late orders are accepted to provide excellent customer service (de Koster et al 2007). Therefore, the order picking process needs to be planned carefully such that the requested items are picked as fast as possible in a cost-efficient way. In a warehouse, decisions need to be taken on three major aspects: the picking policy, the routing policy, and the storage policy. For a thorough review on warehousing and order picking, the reader is referred to de Koster et al (2007) and Chen et al (2010).

In the majority of papers, the total route length is minimized (Davarzani and Norrman 2015). When order pickers travel at a constant speed and there is no congestion, the total order picking time is minimized as well (Chen et al 2010). The shorter the picking time, the sooner the orders are available to be delivered to customers (de Koster et al 2007). Additionally, by minimizing the route lengths and as such the picking times, a single order picker can pick more orders during his working hours, or less order pickers are needed to pick the same number of orders. Consequently, lower labor costs are incurred (Ruben and Jacobs 1999).

In our problem, a single order picking policy is used as a first step to integrate both an OPP and a VRP. Single order picking is easy to operate and orders need not be sorted afterwards which reduces the possibility of errors. As the customer orders and the storage locations of each item are considered to be known in advance in our problem, the tour length of each order can be determined based on the routing strategy applied. Consequently, based on the tour lengths and the travel speed of the order pickers, the order picking times can be predetermined in a separate optimization problem. The total order picking time is the sum of the picking time of all orders. Regular and temporary order pickers travel at the same speed. Thus, the picking time of a specific order is the same regardless it is picked by a regular or a temporary order picker. 
Hence, in contrast with most studies on order picking, in our integrated problem the total route length and picking times are known in advance. The only decision which needs to be made in the OPP is the assignment of orders to regular or temporary order pickers. As the wage of a temporary order picker is higher than that of a regular order picker, orders need only to be assigned to temporary order pickers when a picking schedule with only regular order pickers is not feasible. In the latter scenario, temporary order pickers need to pick the orders with the smallest picking times. Consequently, in order to estimate the impact of the integrated OP-VRP, the total picking costs per minute working for regular and temporary order pickers are minimized instead of minimizing the total distance traveled which is generally the objective function in order picking problems.

\subsection{Vehicle routing problem with release dates}

In the classical VRP, goods need to be distributed from one or more depot(s) to a set of geographically scattered customers by constructing routes along a network in such a way that all requirements are fulfilled and an objective is met. A fleet of vehicles is located at the $\operatorname{depot}(\mathrm{s})$. Both the vehicles and the goods are available at the beginning of the time horizon (Toth and Vigo 2014). A detailed classification and review of classical VRPs can be found in Braekers et al (2016b).

Recently, some studies have considered VRPs in which not all goods are available at the beginning of the time horizon. The moment the goods become available at the depot for delivery to customers is called the release date. Release dates link different levels in a supply chain: production and delivery, or order picking and delivery. This class of problems is called vehicle routing problems with release dates (VRP-rd).

To the best of our knowledge, Cattaruzza et al $(2013,2014,2016)$ are the first ones to investigate a VRP-rd and extend it to a VRP with time windows and release dates $(V R P T W-r d)$ in which each of the identical capacitated vehicles can conduct multiple trips. The delivery of goods should start within the time window specified. Furthermore, each vehicle has to return to the depot before the end of the time horizon. The objective is to minimize the total time traveled in Cattaruzza et al (2013), and to minimize the total distance traveled in Cattaruzza et al $(2014,2016)$.

Archetti et al (2015a) examine the complexity of a VRP-rd when the graph describing the locations of the depot and the customers has a special structure, either a star or a line. For both graph structures, two cases are considered. In the first case, a single vehicle is available which can conduct multiple trips, while in the second case an unlimited number of vehicles are available which can conduct a single tour. The vehicles have no capacity limitations. For both cases, two different objectives are evaluated: (1) minimize the total traveling distance when there is a delivery deadline, and (2) minimize the maximum value of the sum of travel times and waiting time when there is no delivery deadline. Archetti et al (2015b) investigate a multi-period VRP with release and due dates between which goods need to be delivered by a fleet of homogeneous vehicles. The objective is to minimize the sum of transportation, inventory holding cost, and penalty costs. 
The VRP in our study is most related to the VRP with order available times (or release dates) formulated by Liu et al (2017) in an e-commerce industry. The order available times are the completion times of the order picking and packing process. Liu et al (2017) make use of a fleet of homogeneous capacitated vehicles to deliver the parcels. The objective is to minimize the sum of the vehicle completion times, which include the travel times plus the vehicle departure time at the depot.

Our formulated problem differs from the above mentioned studies in the following ways. First, a fleet of heterogeneous vehicles is used instead of a single or an unlimited number of uncapacitated vehicles in Archetti et al (2015a), or a homogeneous capacitated fleet in Cattaruzza et al (2013, 2014, 2016), Archetti et al (2015b) and Liu et al (2017). In reality, a company often owns vehicles with different capacity restrictions and cost structures. As such, a heterogeneous fleet is a more realistic assumption. Second, hard time windows are considered in our problem. Archetti et al (2015a,b) and Liu et al (2017) do not consider time windows. In Archetti et al (2015b) and the first case of Archetti et al (2015a), a delivery deadline is imposed. More and more e-commerce companies offer their customers the opportunity to select a time window within which they want to be delivered. Third, a single-period problem is considered instead of a multi-period problem as in Archetti et al (2015b). Finally, each vehicle can conduct a single trip instead of multiple trips.

Despite VRP-rd did not receive a lot of attention in the literature, in integrated PSVRPs, where production and distribution are linked, release dates are indispensable. These release dates are equal to the completion times of the production process. Although the term release dates is not used, it is required that the distribution can only start after the goods are produced in these integrated studies. In mathematical models often a constraint is added which requires that the departure time of the vehicle or the arrival time at the customer is larger than the completion time of the production process, e.g., in Park and Hong (2009) and Ullrich (2013). Arda et al (2014) formulate a multi-period vehicle loading problem with stochastic release dates. This problem intermediates between a purely uncoordinated approach and a fully integrated approach. The problem investigates whether transportation decisions can be improved when forecasts about future releases of items from production are taken into account.

\subsection{Integrated problem}

Most studies on the integration of supply chain functions deal with a production context and focus on relatively simple delivery operations, such as direct shipments to customers. A review on integrated production-distribution problems can be found in Chen (2010) and Wang et al (2015). In the last decade, integrated studies in which distribution operations are formulated as a VRP have received more attention in the literature (Chen 2010; Moons et al 2017). In these PS-VRPs often a single or parallel machine environment is considered. Production, setup, and inventory costs are often neglected. In recent studies, a heterogeneous fleet of vehicles is available and time windows are generally included in the vehicle routing subproblem. A more detailed analysis of the characteristics of integrated PS-VRPs can be found in Moons et al (2017). 
Zhang et al (2016) consider the integration of an on-line order picking system, in which customer orders arrive dynamically over time, with a distribution system. Orders need to be batched in order to maximize the number of orders delivered within the shortest service time. To the best of our knowledge, Zhang et al (2016) are the first authors to study the integration of an OPP with distribution operations in an ecommerce environment. However, delivery is outsourced to a 3PL service provider and as such fixed departure times of vehicles at the DC are considered. The authors highlight the integration of order picking processes and VRP as a future research direction. Our paper is an answer to this call for more research on integrated order picking-vehicle routing problems.

Whereas Zhang et al (2016) basically focus on the order picking process and include more realistic characteristics, such as dynamic arrival of orders and batch picking, in our study, the focus is on the integration order picking and vehicle routing, and its benefits. The inclusion of a VRP into the integrated problem is more realistic as in an e-commerce context, several customer orders are delivered in a single route. Furthermore, Zhang et al (2016) maximize the number of delivered orders and minimize the service time. In the problem formulated in this study, the total costs of picking and distribution are minimized in order to indicate the value of integration compared with an uncoordinated approach.

Low et al $(2013,2014$, in press) investigate the integration of a practical scheduling problem in a DC with a VRP. Nevertheless, in their problem formulation production concepts are used. For instance, to calculate the processing time of an order in the DC a unit processing time of a retailer is multiplied by the demand of that retailer. For example, if the unit processing time is equal to 5 and a customer orders 7 units, the total picking time becomes 35 . However, order picking processing times are not proportional to the demand requested. Travel times between different picking locations are the major component in order picking times (Tompkins et al 2003; de Koster et al 2007), which are independent of the quantity ordered. The travel times depend on the storage locations of the goods in the warehouse.

The problem described in this paper differs from the problem formulated by Low et al (2013, 2014, in press) in the following ways. First, instead of using a single workstation (or order picker) for picking and packing, multiple order pickers are available in our study. Second, the objective in Low et al (2013) is to minimize the time required to process and deliver all customer orders. However, a processing time in order picking proportional to customer demand is incorporated, which is not realistic in order picking. As such, in our paper the appropriate order picking terminology is used instead of production concepts. Third, in Low et al (2014, in press) costs need to be minimized, but only transportation costs and penalty costs incurred for violation of time windows are incorporated; order processing costs in the DC are neglected. Besides delivery costs, order picking costs are also included in our study. Penalty costs are not relevant since in our study hard time windows which may not be violated are considered. Finally, a limited number of heterogeneous vehicles are available whereas in Low et al (2013) homogeneous vehicles are used and in Low et al (2014, in press) an unlimited number of heterogeneous vehicles. Additionally, in the problem formulated in this paper more real-life characteristics are applied, such as setup times and vehicle loading times. While the aim of Low et al (2013, 2014, 
in press) is to develop an efficient algorithm to solve the integrated problem, in our study indicating the value of integration is the main focus.

\section{Mathematical formulation}

Mixed integer linear programming (MILP) formulations for each subproblem, i.e., OP and VRP, are provided in Sect. 5.2 and 5.3, respectively. In Sect. 5.4, a MILP model is presented for an integrated OP-VRP approach.

\subsection{Notation}

The sets, indices, parameters, and decision variables needed in the mathematical models are defined as follows:

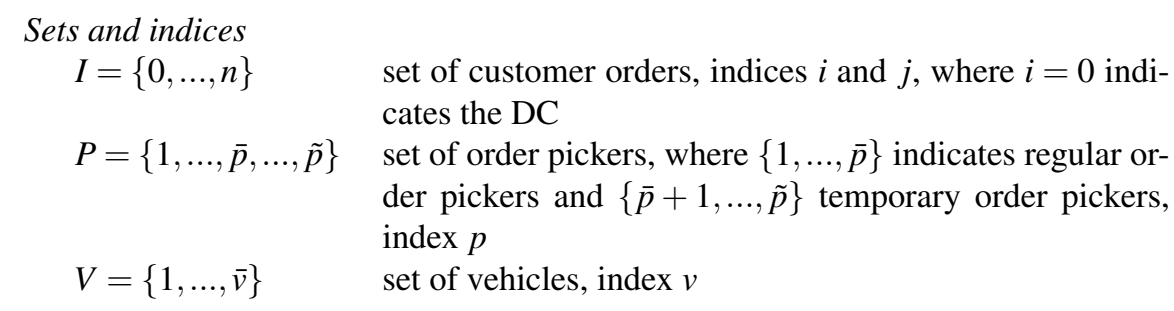

The indices are related in the following way: an order $i$ is picked by an order picker $p$ in the warehouse and thereafter delivered to the customer by a vehicle $v$.

$\begin{array}{cl}\text { Parameters } & \\ C_{p} & \text { capacity of order picker } p, \text { in number of items } \\ C_{v} & \text { capacity of vehicle } v, \text { in number of items } \\ w_{i} & \text { capacity utilization of customer order } i(i \geq 1), \text { in number } \\ & \text { of items } \\ p t_{i} & \text { picking time of customer order } i(i \geq 1), \text { in minutes } \\ o d_{i} & \text { order date of customer order } i(i \geq 1), \text { in minutes } \\ p d & \text { picking due date, in minutes } \\ r d_{i} & \text { release date for delivery of customer order } i(i \geq 1), \text { in } \\ & \text { minutes } \\ s_{i} & \text { service time at delivery destination of customer order } i, \\ & \text { in minutes; index } i=0 \text { indicates the loading time at the } \\ & \text { DC } \\ t_{i j} & \text { travel time between delivery destination of customer or- } \\ & \text { der } i \text { and delivery destination of customer order } j, \text { in min- } \\ & \text { utes. When two orders belong to the same customer, then } \\ & t_{i j}=0 .\end{array}$




$$
\left[a_{i}, b_{i}\right]
$$

cpreg $_{p} /$ cptemp $_{p}$ $w t_{\text {reg }}^{\max } / w t_{\text {temp }}^{\max }$

$$
\text { NPick }_{\max }
$$

$f_{v}$

$c t_{v}$

$T L_{\max }$

Decision variables

$\mathrm{STO}_{i}$

CTO

$S T T_{v}$

$T L_{v}$

$D T_{i}$

$X_{i p}$

$U_{i j p}$

$Y_{i v}$

$Z_{i j v}$ lower bound $a_{i}$ and upper bound $b_{i}$ of delivery time window of customer order $i(i \geq 1)$; index $i=0$ indicates the time window in which vehicles can leave and return to the DC, in minutes

wage per minute of a regular/temporary order picker $p$ maximum working time of a regular/temporary order picker, in minutes

maximum number of order pickers that can work simultaneously

fixed cost of using vehicle $v$

variable cost per minute traveling with vehicle $v$, including both the wage of the driver and the fuel costs maximum tour length, in minutes

start time of picking customer order $i(i \geq 1)$, in minutes completion time of picking customer order $i(i \geq 1)$, in minutes

start time of loading vehicle $v$, in minutes

tour length of vehicle $v$, in minutes

delivery time of customer order $i(i \geq 1)$, i.e., start of unloading, in minutes

binary variable which is equal to $1\left(X_{i p}=1\right)$ if customer order $i$ is picked by order picker $p$

binary variable which is equal to $1\left(U_{i j p}=1\right)$ if customer order $j$ is picked immediately after customer order $i(i \neq$ $j$ ) by order picker $p$

binary variable which is equal to $1\left(Y_{i v}=1\right)$ if customer order $i$ is delivered by vehicle $v$

binary variable which is equal to $1\left(Z_{i j v}=1\right)$ if customer order $i$ is delivered immediately before customer order $j$ $(i \neq j)$ by vehicle $v$

\subsection{Order picking subproblem}

In the OP subproblem, a picking due date before which all orders should be picked needs to be respected in such a way that the vehicle delivering the orders can leave on time. This due date is considered as the time the vehicle arrives at the DC to pick up all the orders. The new proposed MILP for the OPP is formulated as a VRP. In both a VRP and an OPP, a sequence needs to be determined. For each order picker, a picking sequence is determined which starts and ends with a dummy order 0 . The order picking time and capacity utilization of this dummy order are equal to zero.

$$
\min \sum_{i=1}^{n} p t_{i} \cdot \sum_{j=0}^{n} \sum_{p=1}^{\bar{p}} \operatorname{cpreg}_{p} \cdot U_{i j p}+\sum_{i=1}^{n} p t_{i} \cdot \sum_{j=0}^{n} \sum_{p=\bar{p}+1}^{\tilde{p}} \operatorname{cptemp}_{p} \cdot U_{i j p}
$$


subject to

$$
\begin{aligned}
& \sum_{p=1}^{\tilde{p}} X_{i p}=1, \quad \forall i \in I \backslash\{0\} \\
& X_{i p}=\sum_{j=0}^{n} U_{i j p}=\sum_{j=0}^{n} U_{j i p}, \quad \forall i \in I, p \in P, i \neq j \\
& \sum_{j=1}^{n} U_{0 j p} \leq 1, \quad \forall p \in P \\
& S T O_{i} \geq o_{i}, \quad \forall i \in I \backslash\{0\} \\
& S T O_{j} \geq C T O_{i}-M^{1} \cdot\left(1-\sum_{p=1}^{\tilde{p}} U_{i j p}\right), \quad \forall i, j \in I \backslash\{0\}, i \neq j, M^{1}=p d \\
& C T O_{i}=S T O_{i}+p t_{i}, \quad \forall i \in I \backslash\{0\} \\
& C T O_{i} \leq p d, \quad \forall i \in I \backslash\{0\} \\
& w_{i} \cdot \sum_{j=0}^{n} U_{i j p} \leq C_{p}, \quad \forall i \in I \backslash\{0\}, p \in P \\
& \sum_{p=1}^{\tilde{p}} \sum_{j=1}^{n} U_{0 j p} \leq N P i c k_{\max } \\
& \sum_{i=1}^{n} p t_{i} \cdot \sum_{j=0}^{n} U_{i j p} \leq w t_{r e g}^{\max }, \quad \forall p=1, \ldots, \bar{p} \\
& \sum_{i=1}^{n} p t_{i} \cdot \sum_{j=0}^{n} U_{i j p} \leq w t_{i n t}^{\max }, \quad \forall p=\bar{p}+1, \ldots, \tilde{p} \\
& \mathrm{CTO}_{i}, S T \mathrm{O}_{i} \geq 0, \quad \forall i \in I \backslash\{0\} \\
& X_{i p}, U_{i j p} \in\{0,1\}, \quad \forall i, j \in I, i \neq j, p \in P
\end{aligned}
$$

The objective function (1) of the order picking subproblem minimizes the sum of the variable picking costs both for regular and temporary order pickers. Constraint (2) guarantees that each customer order is assigned to exactly one order picker. Constraint (3) specifies that the number of predecessors and successors of a customer order needs to be equal. Inequality (4) expresses that each order picker can have at most one order to be picked as first in a sequence. Inequality (5) indicates the earliest possible start time for picking a customer order. Constraints (6) and (7) compute the start time and completion time of picking a customer order, respectively. Inequality (8) impedes that the picking due date is violated. Constraint (9) ensures that the capacity of the order picker is not violated. The maximum number of order pickers working at a time is restricted by Inequality (10). Constraints (11) and (12) limit the working time of regular and temporary order pickers, respectively. Constraints (13) and (14) define the domains of the decision variables. 
5.3 Vehicle routing subproblem

In contrast to a classical VRP, not all customer orders are available for delivery at the same moment in time. In this paper, orders become available for delivery when the order picking process for that order in the DC is completed. This completion time $C T O_{i}$ can be considered as the release date of order $i$ in the VRP. The release dates are considered to be known in the VRP and are used as input from the order picking subproblem. The formulation is based on Ullrich (2013) with the following modifications: (1) All vehicles are available at the beginning of the time horizon and can conduct a single trip. (2) Hard time windows are considered instead of a soft upper bound. When a vehicle arrives late, it is possible that the customer is no longer at home to accept the parcel. (3) As tardy deliveries are not allowed, instead of minimizing the total tardiness the total costs related to the tour lengths and vehicle usage need to be minimized. (4) The route length of each vehicle trip is limited. Restricting the route lengths and minimizing these is similar to the studies of Moon et al (2012) and Belhaiza et al (2014). In Moon et al (2012), the sum of the travel cost, regular driver labor cost and overtime driver labor cost is minimized, and in Belhaiza et al (2014) the sum of the travel times and the waiting times is minimized. These two objective functions are equivalent to minimizing the route lengths. A MILP model for a VRPTW-rd is formulated below.

$$
\min \sum_{v=1}^{\bar{v}} f_{v} \cdot Y_{0 v}+\sum_{v=1}^{\bar{v}} c t_{v} \cdot T L_{v}
$$

subject to

$$
\begin{array}{ll}
Z_{i j v}=0, & \forall i, j \in I \backslash\{0\}, i \neq j, \\
\sum_{v=1}^{\bar{v}} Y_{i v}=1, & a_{i} \geq b_{j} \\
Y_{0 v} \geq Y_{i v}, & \forall i \in I \backslash\{0\} \\
Y_{j v}=\sum_{i=0}^{n} Z_{i j v}=\sum_{i=0}^{n} Z_{j i v}, & \forall i \in I \backslash\{0\}, v \in V \\
\sum_{i=1}^{n} w_{i} Y_{i v} \leq C_{v}, & \forall j \in I, v \in V, i \neq j \\
r d_{i} \leq S T T_{v}+M_{i}^{2} \cdot\left(1-Y_{i v}\right), & \\
& \forall v \in V \\
a_{0} \leq S T T_{v}, & \forall i \in I \backslash\{0\}, v \in V, \\
S T T_{v}+s_{0}+t_{0 j} \leq D T_{j}+M_{j}^{3} \cdot\left(1-Z_{0 j v}\right), & M_{i}^{2}=r d_{i} \\
& \forall v \in V \\
D T_{i}+s_{i}+t_{i j} \leq D T_{j}+M_{i j}^{4} \cdot\left(1-\sum_{v=1}^{\bar{v}} Z_{i j v}\right), & \forall j \in I \backslash\{0\}, v \in V, j \in I \backslash\{0\}, i \neq j, \\
& M_{j}^{3}=b_{0}+s_{0}+t_{0 j}-a_{j}
\end{array}
$$




$$
\begin{array}{ll} 
& M_{i j}^{4}=b_{i}+s_{i}+t_{i j}-a_{j} \\
a_{i} \leq D T_{i} \leq b_{i}, & \forall i \in I \backslash\{0\} \\
D T_{i}+s_{i}+t_{i 0} \leq b_{0}+M_{i}^{5} \cdot\left(1-\sum_{v=1}^{\bar{v}} Z_{i 0 v}\right), & \forall i \in I \backslash\{0\}, \\
& M_{i}^{5}=b_{i}+s_{i}+t_{i 0}-b_{0} \\
D T_{i}+s_{i}+t_{i 0}-S T T_{v} \leq T L_{v}+M_{i}^{6} \cdot\left(1-Z_{i 0 v}\right), & \forall i \in I \backslash\{0\}, v \in V, \\
& M_{i}^{6}=b_{i}+s_{i}+t_{i 0} \\
T L_{v} \leq T L_{\max }, & \forall v \in V \\
D T_{i} \geq 0, & \forall i \in I \backslash\{0\} \\
S T T_{v}, T L_{v} \geq 0, & \forall v \in V \\
Y_{i v}, Z_{i j v} \in\{0,1\} & \forall i, j \in I, v \in V
\end{array}
$$

In the objective function (15) of the VRPTW-rd the sum of the fixed vehicle costs and the variable costs based on the total tour lengths is minimized. Constraint (16) ensures that a customer cannot be visited before another customer if his time window is after this of the latter one. Constraint (17) ensures that each customer order is delivered by exactly one vehicle. Inequality (18) indicates that the DC is visited in each tour. Constraint (19) indicates that each customer order location is entered and left. Constraint (20) guarantees that the capacity of each vehicle is not exceeded. Constraints (21) and (22) indicate the earliest possible start time of a vehicle tour. Inequalities (23)-(24) compute the delivery time of each order. Constraints (22)-(24) are adapted from Braekers et al (2016a). Inequality (25) ensures that the delivery time is within the time window, and (26) that the vehicle is back at the DC on time. The maximum tour length is restricted by Constraints (27) and (28). Constraints (29)-(31) indicate the domain of the decision variables.

\subsection{Integrated order picking-vehicle routing problem}

In the integrated problem both mathematical formulations are combined into a single optimization problem. The order picking process has no due date anymore. The only relevant time-restriction is that orders need to be delivered within the specified time windows. By solving the subproblems simultaneously, more flexibility is possible. Vehicles can leave the plant at any time and as such have no fixed departure time, i.e., picking due date. Therefore, Constraint (8) used in the order picking subproblem is not incorporated in the integrated OP-VRP formulation. Furthermore, the computation of the Big $\mathrm{M}$ changes in Constraint (6) as follows:

$$
\begin{gathered}
S T O_{j} \geq C T O_{i}-M_{i}^{7} \cdot\left(1-\sum_{p=1}^{\tilde{p}} U_{i j p}\right), \quad \forall i, j \in I \backslash\{0\}, i \neq j, \\
M_{i}^{7}=b_{i}-t_{0 i}-s_{0}
\end{gathered}
$$


As already mentioned, the completion times of the order picking in the OP-subproblem in Sect. 5.2 are used as release dates in the VRP-rd in Sect. 5.3. In the integrated approach, the release date $r d_{i}$, which is a parameter, in Constraint (21) is replaced by variable $C T O_{i}$. As such, Constraint (21) becomes:

$$
C T O_{i} \leq S T T_{v}+M_{i}^{7} \cdot\left(1-Y_{i v}\right), \quad \forall i \in I \backslash\{0\}, v \in V, M_{i}^{7}=b_{i}-t_{0 i}-s_{0}
$$

In short, the formulation of the integrated OP-VRP is the following:

$$
\begin{array}{r}
\min \sum_{i=1}^{n} p t_{i} \cdot \sum_{j=0}^{n} \sum_{p=1}^{\bar{p}} \operatorname{cpreg}_{p} \cdot U_{i j p}+\sum_{i=1}^{n} p t_{i} \cdot \sum_{j=0}^{n} \sum_{p=\bar{p}+1}^{\tilde{p}}{ }^{\bar{p}} \text { ptemp }_{p} \cdot U_{i j p}+ \\
\sum_{v=1}^{\bar{v}} f_{v} \cdot Y_{0 v}+\sum_{v=1}^{\bar{v}} c t_{v} \cdot T L_{v}
\end{array}
$$

subject to (2)-(5), (7), (9)-(14), (17)-(20), and (22)-(33).

\section{Computational experiments}

In this section, experiments are executed to evaluate the performance of the mathematical models formulated in Sect. 5. The value of integration is computed by comparing the results of an integrated approach to these of an uncoordinated approach.

\subsection{Data generation}

In order to conduct the experiments, random data instances are generated. The capacity utilization of an order $w_{i}$ is randomly generated from a triangular distribution with a minimum of 1 item, a mode of 2 items, and a maximum of 6 items, which results in an average order size of 3 items, as in Ruben and Jacobs (1999) and Petersen (2000). The capacity of the picking devices is measured in number of items as in, for example, Ruben and Jacobs (1999), de Koster et al (1999), and Henn (2012). All order pickers have the same picking device with a capacity of 20 items. Thus, with the instances used, each order picker is capable to pick every order as the maximum order size is smaller than the picking device capacity. The order processing time $p t_{i}$ is equal to the sum of a setup time, i.e., 2 minutes, and the route time. The route time is randomly generated from $U(8,25)$, where $U\left(x_{1}, x_{2}\right)$ defines the uniform distribution between $x_{1}$ and $x_{2}$. The average order processing time is equal to 18.5 minutes which is equivalent to the data used in Gong and de Koster (2008). The picking due date $p d$ is equal to 240. Thus, the order pickers have at most four hours to complete the picking process for all customer requests. Two regular order pickers are available to pick the orders. Four order pickers can work at a time, and as such at most two temporary order pickers can be hired. The variable picking cost per minute working is equal to 1 and 1.5 for regular and temporary order pickers, respectively. Both regular and temporary order pickers work in a half-day shift, and thus are allowed to work 240 minutes. In the experiments, all orders are available for order picking at the same moment in time and have the same order date. 
In the distribution part of the problem, three vehicles are available with a capacity $C_{v}$ of 100, 50 and 25 items, and a fixed vehicle cost $f_{v}$ of 250, 200 and 150, respectively. The variable travel cost $c t_{v}$ is equal to 1 for all vehicles. Thus, the variable travel costs are equal to the travel times. The $x$-coordinates and $y$-coordinates of the destinations of the customer orders are randomly sampled from $U(0,30)$. The DC is located at the middle of the square, i.e., $(15,15)$. The travel times $t_{i j}$ are equal to the rounded Euclidean distance between the locations of the customer orders. The loading time at the plant $s_{0}$ is fixed at 20 minutes. Unloading times $s_{i}(i \geq 1)$ are uniformly distributed from $U(2,10)$.

In an e-commerce context, companies often propose several time windows from which customers can choose one within which they want to be delivered. In order to obtain a feasible solution, the lower bound of the time window $a_{i}$ should be at least equal to the picking due date plus the loading time at the DC plus the largest possible travel time between the DC and the farthest possible customer location. This customer location is located at the corner of the square. Then, the largest travel time is computed as follows: $t_{0 j}^{\max }=\sqrt{\left(x_{\max } / 2\right)^{2}+\left(y_{\max } / 2\right)^{2}}$. For a square of 30 by 30 , the maximum rounded travel time between the DC and a customer is equal to 22 . The picking due date is at 240 and the loading time at the DC is 20 minutes. Consequently, the lowest value of $a_{i}$ is equal to 282 , i.e., $p d+s_{0}+t_{0 j}^{\max }$. The upper bound of the time window is equal to the lower bound plus 60 minutes. As such, each customer order should be delivered within a one-hour time window. After servicing the last customer in a route a vehicle has to return to the DC. A driver works in 8-hour shift (480 minutes), starting after the picking due date in the uncoordinated approach. Consequently, the time window of the DC is [240,720]. Since time windows of one hour are offered, seven lower bounds for the time window are possible: $\{282,342,402,462,522,582,642\}$.

\subsection{Solution methodology}

In this section, computational experiments are conducted to evaluate the value of integration. Three classes of instances are generated with 10, 15, and 20 customer orders, respectively. For each class, twenty instances are used to test the performance of the uncoordinated and the integrated approaches. Thus, the integrated problem is evaluated for in total 60 instances. The problem class with 10 customer orders located in a square of 30 by 30 is referred to as the basis problem. The instances are tested on an Intel Core i5 with 2.6 GHz and 8GB RAM. CPLEX 12.6.2 from IBM is used as MILP-solver.

\subsubsection{Uncoordinated approach}

In the uncoordinated approach, first the order picking subproblem, formulated in Sect. 5.2, is solved, followed by the VRP, formulated in Sect. 5.3. The vehicles arrive at the DC at the picking due date. As such the orders cannot be loaded onto the vehicle earlier and, therefore, the release date in the VRP of all orders is equal to the picking due date. Thus, $p d=a_{0}=r d_{i}=240$. Consequently, Constraints (21) and (22) 
are the same, and to avoid duplicate constraints the latter one is removed from the mathematical formulation in the experiments. The working time of the drivers starts at the moment they arrive at the DC. Therefore, the computation of the tour lengths starts at the lower bound of the time window of the DC. Constraint (27) is adapted to:

$$
\begin{array}{ll}
D T_{i}+s_{i}+t_{i 0}-a_{0} \leq T L_{v}+M_{i}^{10} \cdot\left(1-Z_{i 0 v}\right), & \forall i \in I \backslash\{0\}, v \in V, \\
& M_{i}^{10}=b_{i}+s_{i}+t_{i 0}-a_{0}
\end{array}
$$

\subsubsection{Integrated approach}

In the integrated approach, the model formulated in Sect. 5.4 is used. The same data is used as in the uncoordinated approach. However, the picking due date is not necessary anymore, as mentioned before. Due to the increased flexibility, vehicles can arrive at the DC at any moment in time, which results in the following time window of the DC: $[0,720]$. Again, Constraint (22) is removed from the formulation as this is equivalent to the nonnegativity constraint (30). The working time of the drivers starts at the moment the vehicle is loaded.

\subsection{Results: value of integration}

\subsubsection{Impact of number of customer orders}

The results of the two approaches are compared to compute the value of integration. The cost reduction rate (CRR), which represents the value of integration, is computed as follows: $100 \cdot\left[\left(T C_{u n c}-T C_{i n t}\right) / T C_{u n c}\right]$, with $T C_{u n c}$ the total costs of the uncoordinated approach and $T C_{i n t}$ these of the integrated approach.

Table 2 Impact of number of customers orders

\begin{tabular}{rrrrrr}
$n$ & $\mathrm{CRR}(\%)$ & $\Delta T C_{\text {cpreg }}(\%)$ & $\Delta T C_{\text {cptemp }}(\%)$ & $\Delta T C_{c t_{v}}(\%)$ & $\Delta T C_{f_{v}}(\%)$ \\
\hline 10 & 12.65 & 0.00 & 0.00 & 22.99 & 0.00 \\
15 & 11.83 & 0.00 & 0.00 & 22.61 & 0.00 \\
20 & 11.87 & 0.00 & 0.00 & 24.50 & 0.00
\end{tabular}

In Table 2, the average cost changes over the 20 instances per class, all available at the beginning of the planning horizon, are shown per cost component. The integrated approach always leads to a better solution. The integrated approach results in lower costs with improvements of approximately $12 \%$ on average (CRR), which demonstrates the importance of integration. In the uncoordinated and integrated approach, the same number of regular order pickers $\left(\Delta T C_{\text {cpreg }}\right)$ and number of vehicles $\left(\Delta T C_{f_{v}}\right)$ is used, and as such no savings are obtained on these cost components. No temporary pickers are hired $\left(\Delta T C_{c p t e m p}\right)$ in both approaches. The only difference between the uncoordinated and the integrated approach are the variable travel costs $\left(\Delta T C_{c t_{v}}\right)$.

This difference in variable travel costs is caused by the picking due date in the uncoordinated approach. In this approach, the delivery operations are outsourced to 


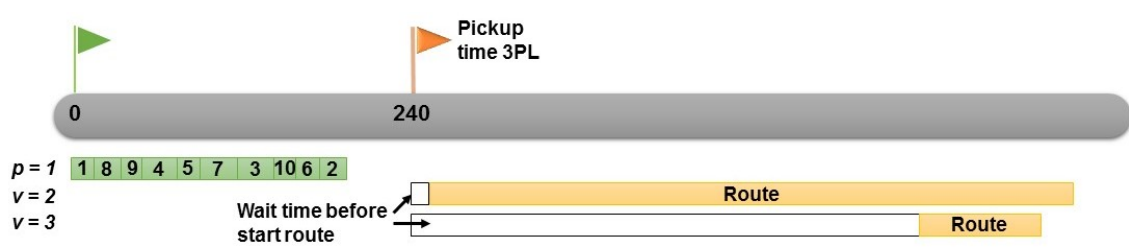

(a) Uncoordinated approach
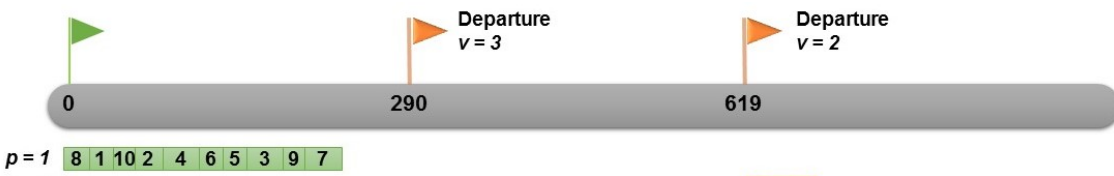

$v=2$

$v=3$

Route

(b) Integrated approach

Fig. 3 Timeline of instance 1 with 10 customer orders and order date $=0$

a 3PL service provider, which picks up the goods daily at the same fixed time. The pickup time does not depend on the number of orders or the associated customer specified delivery time windows. Consequently, even if the customers selected the latest possible delivery time window the pickup time remains the same. Thus, in the uncoordinated approach, the driver arrives at the DC at the pickup time, and consequently the wage of the driver starts at the picking due date. However, the real start of the vehicle tours is often later in time to satisfy the customer delivery time windows. As such, drivers have to wait at the DC before traveling to the first customer in the route, but are being paid. In the integrated approach, as there is no fixed pickup time anymore, the start time of the distribution process is more flexible. The vehicles arrive at the DC just before the real start of the routes, and as such the vehicles do not have to wait. The drivers are paid for the time they actually work. This is illustrated in Fig. 3 for instance 1 with 10 customer orders and $o d_{i}=0$ for all orders. The corresponding vehicle routes are illustrated in Fig. 4.

Although in Table 2 no improvements on fixed vehicle costs are indicated, in larger examples with more customer orders and a longer time horizon cost savings on this component can be obtained. In an uncoordinated approach, all goods ordered after the cut-off time will not be picked up by the 3PL at the pickup time. In an integrated approach, the cut-off time and fixed pickup time are no longer valid. Since vehicles depart at different times throughout the day, these goods can be picked and loaded on a vehicle the same day. Thus, whenever a vehicle leaves the DC to conduct a delivery route, more orders are already being handled in the DC which can be delivered in that route. Hence, in examples spanning a longer time horizon, more consolidation options will be possible. Consequently, less vehicle routes will be necessary, which will result in a lower number of vehicles needed and a lower number of kilometers traveled in total. Nevertheless, in order to quantify the impact of a longer time horizon and more customer orders, additional experiments need to be conducted in future research. 


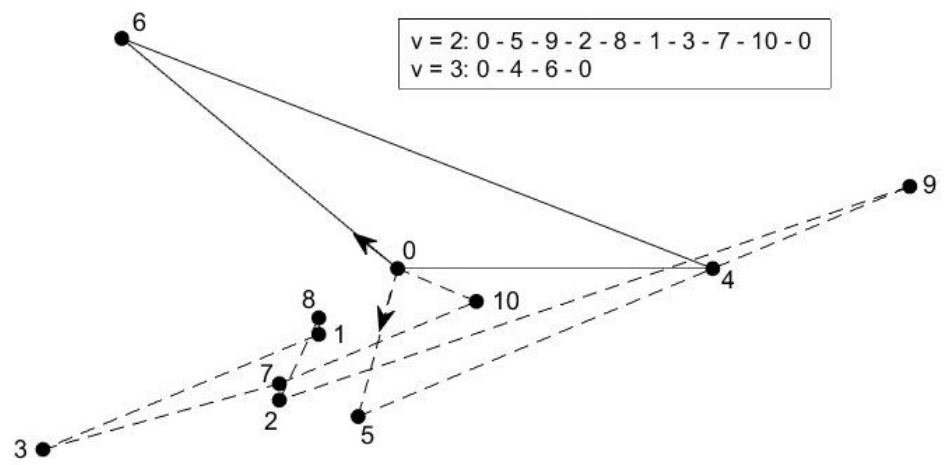

(a) Uncoordinated approach

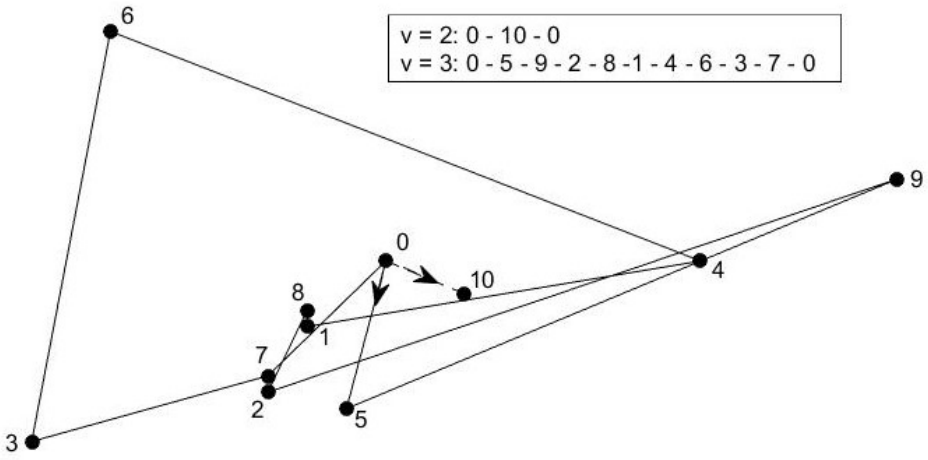

(b) Integrated approach

Fig. 4 Routes of instance 1 with 10 customer orders and order date $=0$

\subsubsection{Impact of order dates}

In order to examine the impact of the moment in time an order is requested, two additional values for the order date are tested on the instances with 10 customer orders: 180 and 210. Each of the 20 instances is tested for each order date value. The other input data of each instance remain the same as in the previous experiments. Thus, the only difference between the experiments in this section and these in Sect. 6.3.1 for the instances with 10 customers is the value of the order date. Average cost savings are indicated in Table 3.

Table 3 Impact of order date on instances with 10 customer orders

\begin{tabular}{lrrrrr}
\multicolumn{1}{c}{$\boldsymbol{o d _ { i }}$} & $\mathrm{CRR}(\%)$ & $\Delta T C_{\text {cpreg }}(\%)$ & $\Delta T C_{\text {cptemp }}(\%)$ & $\Delta T C_{c t_{v}}(\%)$ & $\Delta T C_{f_{v}}(\%)$ \\
\hline 0 & 12.65 & 0.00 & 0.00 & 22.99 & 0.00 \\
180 & 15.75 & -52.47 & 100.00 & 22.99 & 0.00 \\
210 & - & - & - & - & - \\
$\{0,60,120$, & 12.76 & -1.35 & 15.00 & 22.99 & 0.00 \\
$180,210\}$ & & & & &
\end{tabular}


In the uncoordinated approach, all orders still need to be picked before the due date of 240. Since each order picker is allowed to work 240 minutes, in the experiments with order dates of 180 , only 60 minutes per order picker are left to pick orders. Consequently, in the uncoordinated approach temporary order pickers need to be hired, whereas in the integrated approach the regular order pickers can pick all orders on time. This results in higher labor costs for the order pickers. Furthermore, with an order date of 210 , the instances cannot be solved in the uncoordinated approach. With this order date, each order picker has 30 minutes left to pick orders. In total, with four order pickers 120 minutes are available. However, the total time needed to pick all orders is larger than 120 minutes in all generated instances. Thus, no feasible solution can be found for these instances. In the integrated approach, no picking due date has to be respected. All order pickers can work 240 minutes. In four instances temporary order pickers need to be hired. The value of integration increases with a later order date. The average cost savings (CRR) with an order date of 180 is $15.75 \%$ compared to an average CRR of $12.65 \%$ with an order date of 0 . This is mainly caused by the higher picking costs in the uncoordinated approach due to the higher number of order pickers required. The total regular picking cost $\left(\Delta T C_{\text {cpreg }}\right)$ increases, but this is compensated by a decrease in total temporary picking cost $(\Delta$ $T C_{\text {cptemp }}$ ).

Thus, the total time needed to pick and deliver all orders can be shortened in the integrated approach compared to the uncoordinated approach. In practice, B2C e-commerce companies offer customers the possibility to select the time window in which they want the parcel to be delivered, often at an extra charge. By integration, the company can allow customers to place their orders later in time and still offer the same delivery time window options to their customers, which results in a faster delivery. In other words, at each moment of time a customer places an order, more and earlier time window options from which the customer can choose during the ordering process, are available. Hence, integration can lead to a higher service level perceived by the customers.

In the previously executed experiments, all orders have the same order date. The experiments with order date values equal to 180 and 210 are worst-case scenarios in which all orders are placed close to the picking due date in the uncoordinated approach. Therefore, additional experiments are conducted in which the orders do not have a common order date. The order dates are more spread over the time horizon. The same instances with 10 customer orders are used, but the orders have a different order date within an instance. The possible order dates are $\{0,60,120,180,210\}$. Thus, the system is updated every hour, and a last time 30 minutes before the due date of 240. Similar findings as in the experiments with $o d_{i}=180$ are observed, as indicated in Table 3 . The value of integration (CRR) is slightly higher compared with the instances having $o d_{i}=0$. The increase in the total picking cost of regular pickers $\left(\Delta T C_{\text {cpreg }}\right)$ is compensated by savings in the total picking cost of temporary pickers $\left(\Delta T C_{\text {cptemp }}\right)$. Hence, even in a scenario where orders arrive at different points in time, integration is valuable. 
Table 4 Impact of cost parameters on instances with 10 customer orders and an order date of 0

\begin{tabular}{lrrrrr}
$c t_{v}$ & $\mathrm{CRR}(\%)$ & $\Delta T C_{\text {cpreg }}(\%)$ & $\Delta T C_{\text {cptemp }}(\%)$ & $\Delta T C_{c t_{v}}(\%)$ & $\Delta T C_{f_{v}}(\%)$ \\
\hline 1 & 12.65 & 0.00 & 0.00 & 22.99 & 0.00 \\
1.5 & 14.90 & 0.00 & 0.00 & 25.45 & -7.50 \\
2 & 17.03 & 0.00 & 0.00 & 29.29 & -22.32
\end{tabular}

\subsubsection{Impact of cost parameters}

In the experiments in Sect. 6.3.1, the picking cost of the regular order pickers and the variable travel cost have the same value, i.e., cpreg $_{p}=c t_{v}=1$. In order to investigate the impact of an increase in, for example, fuel price, experiments with higher values for the variable travel cost $c t_{v}$ are conducted. The same instances as in the basis problem with 10 customer orders are used with the only difference being the value of $c t_{v}$ which is equal to 1.5 or 2 . Summarized results are set out in Table 4. The results show that the value of integration (CRR) increases with the variable travel cost. The higher the variable travel cost, the more valuable integration is. The total picking costs do not change in the integrated approach. Whereas in the experiments with a variable travel cost of 1 no difference in the total fixed vehicle cost $\left(\Delta T C_{f_{v}}\right)$ is observed, in the experiments with a higher variable travel cost an increase in the total fixed vehicle cost is noticed. When the variable travel cost is higher, it can be more beneficial to conduct more routes if there is a considerable amount of waiting time with a lower number of vehicles. Thus, the higher total vehicle fixed cost is compensated by a reduction in waiting time per vehicle route. This leads to a decrease in the total variable travel cost $\left(\Delta T C_{c t_{v}}\right)$ incurred. As can be seen in Table 4, a higher variable travel cost value results on average in a larger decrease of the total variable travel cost.

\subsubsection{Impact of customer distance to the warehouse}

Table 5 Impact of customer distance to the warehouse on instances with 10 customer orders and an order date of 0

\begin{tabular}{crrrrr} 
Square size & CRR $(\%)$ & $\Delta T C_{c p r e g}(\%)$ & $\Delta T C_{c p t e m p}(\%)$ & $\Delta T C_{c t v}(\%)$ & $\Delta T C_{f_{v}}(\%)$ \\
\hline 20x20 & 10.05 & 0.00 & 0.00 & 20.90 & -3.75 \\
30x30 & 12.65 & 0.00 & 0.00 & 22.99 & 0.00 \\
40x40 & 18.81 & 0.00 & 0.00 & 33.18 & 0.00
\end{tabular}

In the basis problem, customers are located in a square of 30 by 30 . In this section, experiments are conducted on the instances with 10 customer orders and an order date of 0 in which customers are located in a smaller (20x20) or larger (40x40) square. Adapting the square size influences the available time windows since the earliest lower bound of a time window is computed as follows: $p d+s_{0}+t_{0 j}^{\max }$. The largest travel time $t_{0 j}^{\max }$ changes when the square size is modified. The largest travel time in a $20 \times 20$-square and a $40 \times 40$-square is 15 and 29 , respectively. The corresponding earliest lower bounds are 275 and 289. Compared to the basis problem with a 30x30square, the earliest lower bound is 7 minutes earlier or 7 minutes later. Thus, in the 
instances, the time windows for each order are updated according to the new time window bounds.

Table 5 shows average savings over the 20 instances tested. The experiments indicate that the larger the square in which customers are located, the higher the value of integration due to higher savings in total variable travel cost $\left(\Delta T C_{c t_{v}}\right)$. When customers are located in a larger square, the average distance between two customers is larger. Hence, more vehicles are needed to deliver all orders within their time windows. Consequently, in problems with a larger square, more vehicles arrive at the DC at the picking due date in the uncoordinated approach compared to problems with a smaller square. However, the vehicles have to wait before they depart. During the waiting time a variable travel cost is incurred. The more vehicles needed the higher the total waiting time. In the integrated approach, the vehicles arrive at the exact departure time at the DC. Accordingly, there is no waiting time at the depot, and thus the total variable travel costs decrease. Thus, with a larger square, the waiting time for a higher number of vehicles is reduced which leads to higher total savings in comparison with a smaller square size.

\subsubsection{Computation times}

Table 6 Computation times of integrated OP-VRP

\begin{tabular}{|c|c|c|c|c|}
\hline & & $\begin{array}{l}\text { Minimum } \\
\text { time }(\mathrm{s})\end{array}$ & $\begin{array}{l}\text { Average } \\
\text { time }(\mathrm{s})\end{array}$ & $\begin{array}{l}\text { Maximum } \\
\text { time (s) }\end{array}$ \\
\hline Basis scenario & $\begin{array}{l}n=10 \\
o d_{i}=0 \\
c t_{v}=1 \\
\text { square }=30 \times 30\end{array}$ & 0.28 & 1.91 & 9.30 \\
\hline $\begin{array}{l}\text { Changing } \\
\text { parameter }\end{array}$ & $\begin{array}{l}\text { Parameter } \\
\text { value }\end{array}$ & $\begin{array}{l}\text { Minimum } \\
\text { time }(\mathrm{s})\end{array}$ & $\begin{array}{l}\text { Average } \\
\text { time (s) }\end{array}$ & $\begin{array}{l}\text { Maximum } \\
\text { time (s) }\end{array}$ \\
\hline$n$ & $\begin{array}{l}15 \\
20\end{array}$ & $\begin{array}{r}4.23 \\
33.49\end{array}$ & $\begin{array}{r}22.86 \\
4,965.16\end{array}$ & $\begin{array}{r}141.78 \\
25,774.23\end{array}$ \\
\hline$o d_{i}$ & $\begin{array}{l}180 \\
210\end{array}$ & $\begin{array}{l}0.22 \\
0.28\end{array}$ & $\begin{array}{r}1.68 \\
982.56\end{array}$ & $\begin{array}{r}8.47 \\
12,612.72\end{array}$ \\
\hline & $\begin{array}{l}\{0,60, \quad 120, \\
180,210\}\end{array}$ & 0.20 & 1.63 & 6.55 \\
\hline$c t_{v}$ & $\begin{array}{c}1.5 \\
2\end{array}$ & $\begin{array}{l}0.25 \\
0.31\end{array}$ & $\begin{array}{l}2.46 \\
2.81\end{array}$ & $\begin{array}{l}13.55 \\
11.97\end{array}$ \\
\hline Square size & $\begin{array}{l}20 \times 20 \\
40 \times 40\end{array}$ & $\begin{array}{l}0.20 \\
0.25\end{array}$ & $\begin{array}{l}1.17 \\
1.94\end{array}$ & $\begin{array}{l}6.56 \\
6.27\end{array}$ \\
\hline
\end{tabular}

Table 6 provides the minimum, average and maximum computation time for each problem scenario tested. In the integrated approach, the instances with 10 and 15 customer orders can be solved in less than one minute on average. The more customer orders are included, the more time is needed to find the optimal solution, with up to approximately $26,000 \mathrm{~s}(7 \mathrm{~h})$ to solve an instance with 20 orders. Thus, to solve real-world instances with a larger number of orders a heuristic solution method is 
needed. Additionally, later order dates make the problem more complex as the planning horizon becomes shorter. Thus, the average computation time increases in the experiments with order dates equal to 180 and 210. Furthermore, the higher the value of the variable travel time, the higher the average computation time to obtain the optimal solution. Similarly, the size of the square in which customers are located and the computation time are positively related.

\subsubsection{Results: conclusion}

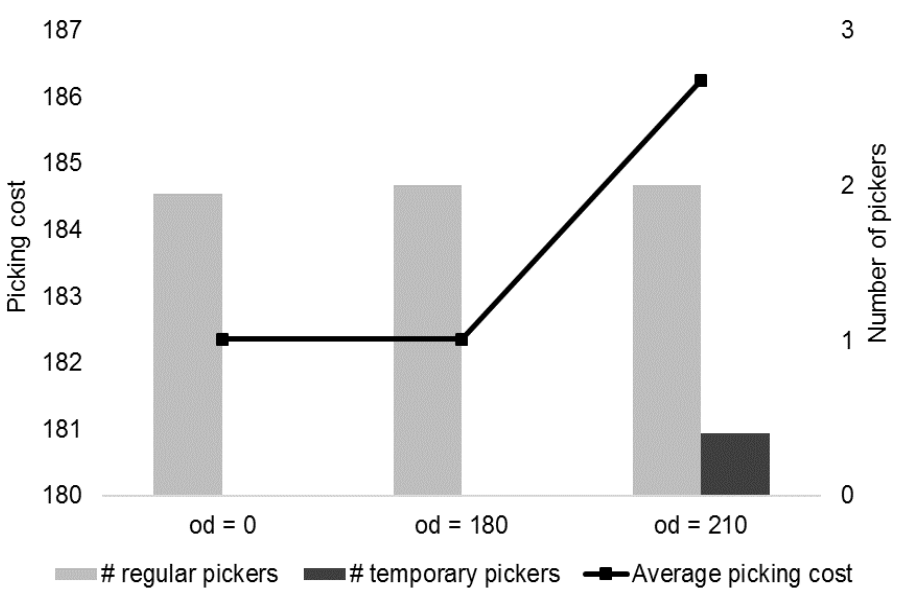

Fig. 5 Trade-off personnel costs and service level in the integrated approach

To conclude, integration in a $\mathrm{B} 2 \mathrm{C}$ e-commerce context has following advantages compared to the uncoordinated approach: (1) a lower number of temporary order pickers are needed, which leads to cost savings; and, (2) a higher service level can be offered as companies allow customers to order later in time and are still able to deliver within the same time windows. However, allowing these late orders implies that more orders need to be picked closer to the departure time of the vehicles. Consequently, more order pickers need to be hired compared to the case of earlier order dates which results in higher personnel costs. As such, there is a trade-off between customer service offered and personnel costs incurred, which is illustrated in Fig. 5 for the instances with 10 customer orders. The average picking costs over the 20 instances tested are represented by the line graph and are indicated on the left axis. The average number of regular and temporary pickers needed over the 20 instances tested are shown in the column chart and are indicated on the right axis. Higher service levels result in higher picking costs and a higher number of order pickers needed. In the uncoordinated approach, due to the maximum number of orders pickers allowed and the fixed arrival times of vehicles at the DC, no feasible solution can be obtained when too many orders are placed close to the due date and not all orders can 
be picked on time, whereas in similar situations the integrated approach can still find feasible solutions due to the higher flexibility, in these situations a feasible solution can still be found. In the experiments conducted in this study, the higher service level is interpreted as allowing the customers to place their orders later in time.

\section{Conclusions and future research opportunities}

B2C e-commerce sales are increasing every year. Customers expect a fast and accurate delivery. In order to fulfill these high customer expectations all supply chain functions have to be optimized simultaneously. In this paper, an order picking process and a vehicle routing problem are integrated into a single optimization problem, i.e., an integrated order picking-vehicle routing problem (OP-VRP), in a $\mathrm{B} 2 \mathrm{C}$ e-commerce context. As in the literature, most integrated problems consider a production environment, first production scheduling and order picking processes are compared before an integrated OP-VRP is formulated. In general, different terminologies are used to define rather similar concepts. The related concepts are linked with each other. For instance, batching and zoning in a warehouse context are related with corresponding processes in a production environment. In both a production context and a warehouse, processed goods need to be delivered to customers. Consequently, there are interdependencies between production and distribution as well as between warehousing and distribution.

According to the authors, it is the first time order picking and vehicle routing decisions are integrated. Mathematical formulations for a single order picking problem, a vehicle routing problem with time windows and release dates, and an integrated problem are presented. The performance of the proposed integrated OP-VRP is compared to an uncoordinated approach in which first an OPP is solved and afterwards a VRP. The total costs obtained by using an uncoordinated approach are compared to the total costs obtained by using the integrated approach.

Experiments indicate that integrating both problems can lead to cost savings of $14 \%$ on average, with even up to approximately $37 \%$. Less temporary order pickers need to be hired in an integrated approach. Vehicles can arrive at the DC at any moment of the day, and thus arrive just before a route needs to start. Consequently, vehicles do not have to wait before the start of a delivery route, which leads to lower driver wages. Additionally, B2C e-commerce companies can offer a higher service level when order picking and vehicle routing decisions are integrated into a single optimization problem. Customers can request their goods later in time and still have the possibility to choose the same delivery time window as an order requested earlier. Companies cannot offer this service in an uncoordinated approach due to the fixed picking due date before which all orders need to be picked. Not enough time is left to pick orders which are requested late. Furthermore, a sensitivity analysis indicates that both the variable travel cost and the size of the square in which the customers are located are positively related with the value of integration.

In this study, experiments with small-size instances with at most 20 customer orders are conducted. The integrated OP-VRP for instances with 10 and 15 customers is capable to find a solution within one minute. However, solving larger instances 
with 20 customer orders can take up to approximately $7 \mathrm{~h}$. A real-world distribution center handles a large number of orders a day. They need to be able to determine order picking schedules and vehicle routes in a small amount of time. Therefore, a heuristic solution method for the integrated OP-VRP needs to be developed.

The formulated integrated OP-VRP can be expanded with batch picking and/or zoning. Furthermore, in a B2C e-commerce context customers can place orders 24/7 and as such demand is generally not known in advance. Determined schedules need to be adapted every time a new order enters the system. Therefore, an integrated OP-VRP in a dynamic context is a valuable further research direction. Moreover, including loading times depending on, e.g., the number of orders, can be included in future models.

Acknowledgements This work is supported by the Interuniversity Attraction Poles Programme initiated by the Belgian Science Policy Office (research project COMEX, Combinatorial Optimization: Metaheuristics \& Exact Methods).

\section{References}

Agatz NAH, Fleischmann M, van Nunen JAEE (2008) E-fulfillment and multi-channel distribution - A review. Eur J Oper Res 187(2):339-356, DOI 10.1016/j.ejor.2007.04.024

Allahverdi A, Soroush HM (2008) The significance of reducing setup times/setup costs. Eur J Oper Res 187(3):978-984, DOI 10.1016/j.ejor.2006.09.010

Allahverdi A, Gupta JND, Aldowaisan T (1999) A review of scheduling research involving setup considerations. Omega-Int J Manage S 27(2):219-239, DOI 10.1016/S0305-0483(98)00042-5

Amorim P, Belo-Filho MAF, Toledo FMB, Almeder C, Almada-Lobo B (2013) Lot sizing versus batching in the production and distribution planning of perishable goods. Int J Prod Econ 146(1):208-218, DOI 10.1016/j.ijpe.2013.07.001

Archetti C, Feillet D, Speranza MG (2015a) Complexity of routing problems with release dates. Eur J Oper Res 247(3):797-803, DOI 10.1016/j.ejor.2015.06.057

Archetti C, Jabali O, Speranza MG (2015b) Multi-period Vehicle Routing Problem with Due dates. Comput Oper Res 61:122-134, DOI 10.1016/j.cor.2015.03.014

Arda Y, Crama Y, Kronus D, Pironet T, Van Hentenryck P (2014) Multi-period vehicle loading with stochastic release dates. EURO J Transp Logist 3(2):93-119, DOI 10.1007/s13676-013-0035-z

Belhaiza S, Hansen P, Laporte G (2014) A hybrid variable neighborhood tabu search heuristic for the vehicle routing problem with multiple time windows. Comput Oper Res 52:269-281, DOI 10.1016/j.cor.2013.08.010

Braekers K, Hartl RF, Parragh SN, Tricoire F (2016a) A bi-objective home care scheduling problem: Analyzing the trade-off between costs and client inconvenience. Eur J Oper Res 248(2):428-443, DOI 10.1016/j.ejor.2015.07.028

Braekers K, Ramaekers K, Van Nieuwenhuyse I (2016b) The vehicle routing problem: State of the art classification and review. Comput Ind Eng 99:300-313, DOI 10.1016/j.cie.2015.12.007

Brucker P (2007) Scheduling algorithms, 5th edn. Springer, Berlin

Cattaruzza D, Absi N, Feillet D, Guyon O, Libeaut X (2013) The Multi Trip Vehicle Routing Problem with Time Windows and Release Dates. In: 10th Metaheuristics International Conference (MIC 2013), Singapore

Cattaruzza D, Absi N, Feillet D (2014) The Multi Trip Vehicle Routing Problem with Time Windows and Release Dates. Working paper EMSE CMP-SFL 2014/1, Ecole des Mines de Saint-Etienne

Cattaruzza D, Absi N, Feillet D (2016) The Multi-Trip Vehicle Routing Problem with Time Windows and Release Dates. Transport Sci 50(2):676-693, DOI 10.1287/trsc.2015.0608

Chang YC, Li VC, Chiang CJ (2014) An ant colony optimization heuristic for an integrated production and distribution scheduling problem. Eng Optimiz 46(4):503-520, DOI 10.1080/0305215X.2013.786062

Chen CM, Gong Y, de Koster RB, van Nunen JA (2010) A Flexible Evaluative Framework for Order Picking Systems. Prod Oper Manag 19(1):70-82, DOI 10.1111/j.1937-5956.2009.01047.x 
Chen ZL (2010) Integrated Production and Outbound Distribution Scheduling: Review and Extensions. Oper Res 58(1):130-148, DOI 10.1287/opre.1080.0688

Chen ZL, Vairaktarakis GL (2005) Integrated Scheduling of Production and Distribution Operations. Manage Sci 51(4):614-628, DOI 10.1287/mnsc.1040.0325

Conway RW, Maxwell WL, Miller LW (1967) Theory of Scheduling. Dover Publications, New York

Davarzani H, Norrman A (2015) Toward a relevant agenda for warehousing research: literature review and practitioners' input. Logist Res 8(1):1-18, DOI 10.1007/s12159-014-0120-1

de Koster MBM, van der Poort ES, Wolters M (1999) Efficient orderbatching methods in warehouses. Int J Prod Res 37(7):1479-1504, DOI 10.1080/002075499191094

de Koster R, Le-Duc T, Roodbergen KJ (2007) Design and control of warehouse order picking: A literature review. Eur J Oper Res 182(2):481-501, DOI 10.1016/j.ejor.2006.07.009

de Koster RMBM (2003) Distribution strategies for online retailers. IEEE T Eng Manage 50(4):448-457, DOI 10.1109/TEM.2003.820135

Ecommerce Europe (2016) European B2C E-commerce Report 2016. Tech. rep., Ecommerce Europe, Brussels

EESC (2003) Industrial change: current situation and prospects - An overall approach. Tech. rep., European Economic and Social Committee, Brussels

EESC (2014) Reshoring of EU industries in the framework of reindustrialisation. Tech. rep., European Economic and Social Committee, Brussels

Elsayed EA, Lee MK, Kim S, Scherer E (1993) Sequencing and batching procedures for minimizing earliness and tardiness penalty of order retrievals. Int J Prod Res 31(3):727-738, DOI $10.1080 / 00207549308956753$

Farahani P, Grunow M, Günther HO (2012) Integrated production and distribution planning for perishable food products. Flex Serv Manuf J 24(1):28-51, DOI 10.1007/s10696-011-9125-0

Fernie J, Sparks L (eds) (2004) Logistics and retail management: insights into current practice and trends from leading experts, 2nd edn. Kogan Page, London

Gong Y, de Koster R (2008) A polling-based dynamic order picking system for online retailers. IIE Trans 40(11):1070-1082, DOI 10.1080/07408170802167670

Graves SC (1981) A Review of Production Scheduling. Oper Res 29(4):646-675, DOI 10.1287/opre.29.4.646

Henn S (2012) Algorithms for on-line order batching in an order picking warehouse. Comput Oper Res 39(11):2549-2563, DOI 10.1016/j.cor.2011.12.019

Henn S (2015) Order batching and sequencing for the minimization of the total tardiness in picker-to-part warehouses. Flex Serv Manuf J 27(1):86-114, DOI 10.1007/s10696-012-9164-1

Henn S, Koch S, Wäscher G (2012) Order Batching in Order Picking Warehouses: A Survey of Solution Approaches. In: Manzini R (ed) Warehousing in the Global Supply Chain, Springer, London, pp 105137

Hultkrantz O, Lumsden K (2001) E-commerce and consequences for the logistics industry. Tech. rep., Department of Transportation and Logistics, Chalmers University of Technology, Göteborg, Sweden

Jacobs FR, Chase RB (2011) Operations and Supply Chain Management, 13th edn. The McGrawHill/Irwin series: Operations and decision sciences, McGraw-Hill/Irwin, New York

Lawler EL, Lenstra JK, Rinnooy Kan AHG, Shmoys DB (1993) Sequencing and Scheduling: Algorithms and Complexity. In: Graves SC, Rinnooy Kan AHG, Zipkin P (eds) Logistics of Production and Inventory, no. 4 in Handbook in Operations Research and Management Science, North-Holland, New York, pp 445-522

Li K, Zhou C, Leung JYT, Ma Y (2016) Integrated production and delivery with single machine and multiple vehicles. Expert Syst Appl 57:12-20, DOI 10.1016/j.eswa.2016.02.033

Liu L, Li K, Liu Z (2017) A capacitated vehicle routing problem with order available time in e-commerce industry. Eng Optimiz 49(3):449-465, DOI 10.1080/0305215X.2016.1188092

Low C, Li RK, Chang CM (2013) Integrated scheduling of production and delivery with time windows Int J Prod Res 51(3):897-909, DOI 10.1080/00207543.2012.677071

Low C, Chang CM, Li RK, Huang CL (2014) Coordination of production scheduling and delivery problems with heterogeneous fleet. Int J Prod Econ 153:139-148, DOI 10.1016/j.ijpe.2014.02.014

Low C, Chang CM, Gao BY (in press) Integration of production scheduling and delivery in two echelon supply chain. Int J Syst Sci: Operations \& Logistics DOI 10.1080/23302674.2015.1110211

Moon I, Lee JH, Seong J (2012) Vehicle routing problem with time windows considering overtime and outsourcing vehicles. Expert Syst Appl 39(18):13 202-13 213, DOI 10.1016/j.eswa.2012.05.081 
Moons S, Ramaekers K, Caris A, Arda Y (2017) Integrating production scheduling and vehicle routing decisions at the operational decision level: A review and discussion. Comput Ind Eng 104:224-245, DOI 10.1016/j.cie.2016.12.010

Park YB, Hong SC (2009) Integrated production and distribution planning for single-period inventory products. Int J Comp Integ M 22(5):443-457, DOI 10.1080/09511920802527590

Petersen CG (2000) An Evaluation of Order Picking Policies for Mail Order Companies. Prod Oper Manag 9(4):319-335, DOI 10.1111/j.1937-5956.2000.tb00461.x

Petersen CG, Schmenner RW (1999) An Evaluation of Routing and Volume-based Storage Policies in an Order Picking Operation. Decision Sci 30(2):481-501, DOI 10.1111/j.1540-5915.1999.tb01619.x

Richards G (2014) Warehouse management: a complete guide to improving efficiency and minimizing costs in the modern warehouse, 2nd edn. Kogan Page Limited, London

Ruben RA, Jacobs FR (1999) Batch Construction Heuristics and Storage Assignment Strategies for Walk/Ride and Pick Systems. Manage Sci 45(4):575-596, DOI 10.1287/mnsc.45.4.575

Rushton A, Oxley J, Croucher P (2001) The handbook of logistics and distribution management, 2nd edn. Kogan Page, London

Tompkins JA, White JA, Bozer YA, Frazelle EH, Tanchoco JMA (2003) Facilities Planning. John Wiley \& Sons, Inc., New York

Toth P, Vigo D (eds) (2014) Vehicle routing: problems, methods, and applications, 2nd edn. SIAM, Philadelphia

Ullrich CA (2013) Integrated machine scheduling and vehicle routing with time windows. Eur J Oper Res 227(1):152-165, DOI 10.1016/j.ejor.2012.11.049

van den Berg JP (1999) A literature survey on planning and control of warehousing systems. IIE Trans 31(8):751-762, DOI 10.1023/A:1007606228790

Van Nieuwenhuyse I, de Koster RBM (2009) Evaluating order throughput time in 2-block warehouses with time window batching. Int J Prod Econ 121(2):654-664, DOI 10.1016/j.ijpe.2009.01.013

VerkehrsRundschau (2015) Amazon baut in Deutschland eigenen Paket-Zustellservice auf. URL http://www.verkehrsrundschau.de/amazon-baut-in-deutschland-eigenen-paket-zustellservice-auf1710022.html, Accessed 08.08.2016

Wang DY, Grunder O, El Moudni A (2015) Integrated scheduling of production and distribution operations: a review. International Journal of Industrial and Systems Engineering 19(1):94-122, DOI 10.1504/IJISE.2015.065949

Zhang J, Wang X, Huang K (2016) Integrated on-line scheduling of order batching and delivery under B2C e-commerce. Comput Ind Eng 94:280-289, DOI 10.1016/j.cie.2016.02.001 